\title{
A MOBILIZAÇÃO DA BASE INDUSTRIAL DE DEFESA NA AMÉRICA DO SUL POR MEIO DA INSERÇÃO BRASILEIRA NO SISTEMA OTAN DE CATALOGAÇÃO
}

\author{
Sabrina Evangelista Medeiros ${ }^{1}$ \\ William de Sousa Moreira²
}

\section{Introdução}

A modernidade trouxe o avanço da ciência e da tecnologia aplicada aos instrumentos de uso da força. Antes manufaturas simples de escudos, espadas e lanças, a complexificação das armas demandou sistemas de produção crescentemente sofisticados, capazes de lidar com a multiplicidade de subsistemas, partes e componentes, na casa dos milhares e, em alguns casos, dos milhões de itens. A gestão de tantos componentes, seja para obtenção de sistemas de armas seja para sua manutenção, passou a ser objeto de preocupação e de esforços de sistematização e controle.

O aprimoramento e o uso de sistemas de catalogação são cada vez mais necessários entre bases industriais de defesa e mercados complexos, com produtos considerados estratégicos e uma cadeia de suprimentos direta ou indiretamente relacionados às bases, e de grande impacto na economia global. Portanto, os sistemas de catalogação podem permitir inserção em mercados de produtores e compradores que afinem parcerias em outros setores da economia, ao mesmo tempo em que acabam por obrigar a normatização

\footnotetext{
I Professora Associada de Relações Internacionais - Programa de Pós-Graduação em Estudos Marítimos da Escola de Guerra Naval (EGN). Doutora em Ciência Política pelo IUPERJ (2005). Email: sabrinamedeiros@yahoo.com

2 Professor do Programa de Pós-Graduação em Estudos Marítimos da Escola de Guerra Naval (EGN). Doutor em Ciência Política pela UFF (20I3). Email: wiliamsm2k@gmail.com As informações, avaliações e conceitos contidos neste capítulo são da exclusiva responsabilidade dos autores, não significando posturas ou visões oficiais das instituições a que se vinculam.
} 
de uma série de procedimentos relacionados à qualidade e demandas internacionais de padronização da produção.

Assim, o impacto causado pela inserção de um país em um sistema, permite a ele o acesso a um número relevante de subsistemas dentro e fora da cadeia de produtos de defesa. Se o impacto deste mercado em matéria de crescimento econômico já foi objeto de estudo sem ter garantido resultados confiáveis quanto à esta relação proporcional, a tendência de tornar os mercados mais eficientes foi traduzida pelo agrupamento de mais atores em sistemas comuns, com o correspondente aumento da confiança.

As mudanças em curso estão associadas ao projeto estabelecido pelos documentos de defesa, depois da criação do Ministério de Defesa. A Política de Defesa Nacional (Decreto no 5.484, de 30 de junho de 2005), atualizada em 2012 como Política Nacional de Defesa (PND), foi seguida pela Estratégia Nacional da Defesa (END), que assumiria o compromisso de orientar a implementação das diretrizes do documento anterior. O Livro Branco de Defesa Nacional, em revisão em 20I7, assim como os demais documentos, também registra o compromisso de estruturar as Forças Armadas "em torno de capacidades, dotando-as de pessoal e material compatíveis com os planejamentos estratégicos e operacionais; e desenvolver o potencial de logística de defesa e de mobilização nacional".

Dentre essas diretrizes estão as parcerias estratégicas, a integração das indústrias de defesa sul-americanas, a capacidade de projeção de poder, a oferta do nível adequado de segurança ao país. Os protocolos que estabeleceram essa padronização e que estão sob o escopo do NATO Codification System (NCS) foram desenvolvidos ao longo dos últimos anos e fizeram do Brasil um dos países emergentes do Sul Global fora da OTAN a se inserir nesse regime evoluindo de país Tier I para Tier $2^{3}$, nível que permite divulgar seus dados de catalogação ou gerenciamento no banco de dados do NCS. Outros países como Cingapura e Malásia evoluíram nessa direção antes do Brasil; Áustria, Austrália e Nova Zelândia o fizeram posteriormente.

Este artigo tem por objetivo descrever e analisar as condicionantes e repercussões da entrada do Brasil no Catálogo da OTAN (NATO Codification System - NCS) para a Base Industrial de Defesa nacional e desenvolvimento do país (cujo acordo é de abril de i997. A hipótese central é que, por meio deste processo, houve um progressivo condicionamento da indústria de defesa e correlatas em benefício de protocolização, o que ampliou a internacionali-

3 Normalmente, as empresas de Nível I (Tier 1) oferecem os processos mais avançados da cadeia de suprimentos. Nos casos de Nível 2 (Tier 2), as empresas são menores e têm menos vantagens técnicas do que as empresas de Nível i e, embora não menos vitais para a cadeia de suprimentos, são mais limitadas no que podem produzir. 
A Mobilização da Base Industrial de Defesa na América do Sul por Meio da Inserção Brasileira no Sistema OTAN de Catalogação

dade e alcance de agentes nacionais, como compradores e vendedores, dentro deste sistema e subsistemas. O artigo está dividido entre o exame do processo de inclusão do Brasil no NSC e das características e propósitos envolvidos e a análise das repercussões para o Brasil. Para isso, antes da análise das repercussões, há uma explicação do método utilizado, uma vez que os objetivos do artigo de consolidam por meio de uma visão prospectiva de médio prazo.

\section{0 sistema de catalogação adotado pela OTAN}

O Brasil passou a ter uma maior demanda por gerenciar sistemas de defesa a partir do final da II GM, quando um número extenso de produtos e parceiros foi incluído no mercado junto às demandas de reorganização pós-guerra. Ainda assim, a sistemática de catalogação que começou nos Estados Unidos foi incorporada pelo Brasil somente ao final da década de I960, com a criação da "Comissão Permanente de Catalogação de Materiais", pelo Estado-Maior das Forças Armadas (EMFA). Já na década de i980, os esforços foram direcionados à criação do sistema de gestão do catálogo, que entrou em operação em I982, com o nome de Sistema Militar de Catalogação (SISMICAT). A normatização desse sistema segundo preceitos de organização do catálogo adotados pela OTAN acontece em I986, mas entre I987 e I994 as Forças Armadas desenvolvem sistemas próprios de administração dos produtos de defesa.

O modelo de catalogação ganhou institucionalidade com a criação em I998 do Centro de Catalogação das Forças Armadas (CECAFA), um ano antes da criação do Ministério da Defesa (MD). A partir disso, entendimentos foram desenvolvidos com os principais países membros da OTAN para que o CECAFA pudesse atuar com base em normativas já praticadas. Mudanças na gestão do CECAFA aconteceram no período de consolidação do Ministério da Defesa até que fosse renomeado como CECADE (Centro de Catalogação de Defesa), assim como o SISMICAT renomeado de SISCADE (Sistema de Catalogação de Defesa). Em 2017 a priorização do tema motivou a criação da CASLODE, nomeadamente, o Centro de Apoio a Sistemas Logísticos de Defesa, onde a catalogação é uma das tarefas. Essas últimas mudanças ocorreram em atendimento ao novo marco legal da Base Industrial de Defesa4 ${ }^{4}$.

O NATO Codification System (NCS) representa, além de um catálogo de produtos, um objeto de planejamento logístico que tem alcance para modificar sistemas nacionais de compra e venda, dadas as exigências de integralização, pertencimento e padronização, intrínsecas à participação neste siste-

4 Lei n I2.598, que estabelece mecanismos de fomento à indústria brasileira de defesa.

192 Austral: Revista Brasileira de Estratégia e Relações Internacionais v.7, n.14, Jul./Dez. 2018 
ma. O método de coleta associado ao catálogo pode ser dividido entre a coleta de dados, a classificação, a identificação, a codificação e o estabelecimento do número de estoque da OTAN. Nesse sistema, os operadores identificam as empresas e os produtos brasileiros pela letra "K" (empresas) e pelo número "I9" (produtos). O sistema de classificação deriva do Nato Codification System (NCS) dos EUA, aperfeiçoado após a II Guerra Mundial, introduzido na OTAN a partir de 1958 (Hunter 2009). O que antes era uma plataforma para operações internacionais de modo a garantir que o militar em operação tenha o item necessário no tempo certo, ganhou maior escopo na atualidade (Hunter 2009).

A amplitude de produtos no catálogo é grande e oferece aos provedores de serviço e usuários maior clareza da disponibilidade de itens e eventuais janelas de oportunidade para o desenvolvimento de tecnologias derivadas e/ ou complementares (Taylor I982). Para efeito de desenvolvimento autóctone em matéria de defesa, a disponibilidade garante visibilidade em empenhos cujos montantes são relativamente elevados e de longo prazo, por conta do fator tecnológico agregado. O principal conceito atribuído à evolução do sistema em tela é o de racionalização, dado que une eficiência do produto à eficiência relacionada ao custo de produção e de sua cadeia logística (Taylor I982). O modelo em questão é governado pelo NATO Group of Directors on Codification (AC/135).

Os processos em curso que são objeto deste estudo encontram-se dotados de uma sistemática que teve aderência do setor de defesa conhecida como "Enterprise Resource Planning" (planejamento de recursos empresariais). O ERP é não somente um modelo de integração de dados para a eficiência da gestão organizacional, mas, no setor da economia de defesa, permite interpelar sujeitos públicos e privados na constituição de uma base logística mais eficiente do que antes. Cabe, portanto, observar o modelo em curso no caso do sistema de catalogação da OTAN no que tange à processos, lógicas e expectativas de resultados que importem tanto aos estudos de economia de defesa quanto a inserção do Brasil nesse cenário para os próximos anos.

Embora reconheçamos que determinadas opções nessa temática tenham um intrínseco caráter político, o interesse em estar no catálogo deriva da busca por maior inserção e eficiência da base industrial de defesa (BID) do Brasil, cujas variáveis são predominantemente comerciais, tecnológicas, econômicas. A Embraer é um exemplo de empresa que, estando no mercado europeu e com ramificação em Portugal, precisou se adequar tanto às exigências contidas no sistema do catálogo, quanto em relação ao ciclo de vida dos produtos (para a venda do $\mathrm{KC}_{390}$ ).

Assim, essa inserção acaba por ampliar os interesses de membros da 
A Mobilização da Base Industrial de Defesa na América do Sul por Meio da Inserção Brasileira no Sistema OTAN de Catalogação

OTAN, podendo trazer resultados positivos para o Brasil nos próximos anos. Um país poderá fazer uso do catálogo, mas deverá fazer a solicitação para ser membro e inserir a sua base industrial, tendo acesso ao sistema de gerenciamento logístico que permite organizar o ciclo de vida de sua base de defesa. Importa destacar que o essencial é avaliar a importância do sistema de catalogação em lide para a BID, no que tange aos determinantes desse processo e aos resultados dele esperados. As implicações de ordem política serão fruto de especulação dos resultados esperados de origem econômica aqui expostos ao fim, na forma de quatro cenários derivados da combinação de expectativas de crescimento ou crise do Brasil e do Sistema OTAN.

O chamado Master Catalogue of References for Logistics (NMCRL) é um projeto coordenado pela Agência de Suporte e Aquisições da OTAN e representa a maior base relativa a inventários de serviços e produtos de defesa no mundo. O sistema já contém cerca de 28 milhões de usuários ativos e mais de I7 milhões de itens numerados, revisados e atualizados de dois em dois meses (aqui consideradas empresas, cadastradas por governos). Os serviços de software disponíveis para catalogação entre parceiros do Sistema OTAN estão categorizados como commercial off-the-shelf (COTS), aqueles cujo uso é imediato e nas condições em que estão, ou government off-the-shelf (GOTS), feitos especialmente para os governos 5 . Enquanto a primeira categoria tem uso somente comercial, essa categoria inclui softwares desenvolvidos pelos governos da Austrália, Espanha, Bulgária e Itália, já usados por outros atores do sistema OTAN.

Outros programas de referência logística são parte da estrutura da OTAN, tal como aqueles ligados à NATO Suppport and Procurement Agency (NSPA). Sob controle da NSPA, o NATO Logistics Stock Exchange (NLSE), por exemplo, tem como funções a troca de ativos em excesso; relatórios sobre os estoques das forças armadas para melhorar o gerenciamento de ativos; gerenciamento de estoque comum e de estoques virtuais; e processamento de pedidos de suporte de emergência da OTAN, inclusive, quanto à eventual liquidação financeira de transações em curso. A questão dos estoques virtuais é um elemento de diferenciação porque o catálogo permite a mobilização de itens que estão disponíveis para agrupamentos eventuais que são considerados virtuais, dado que antecipam soluções baseadas em estoques sobressalentes de atores diversos. (Koch Rodoseck 20ı2; Barbarello et al. 2000).

Por sua vez, os serviços incluídos no Catálogo - onde está inserido o Brasil por agora e, precipuamente, uma plataforma produzida a partir de um método de catalogação - estão divididos entre o sistema de armas, serviços de

5 Ver apresentação do Ministério da Defesa à ABIMAQ - http://camaras.org.br/Arquivos/ Download/Upload/2025.pdf, accessed June 8, 2018.

194 Austral: Revista Brasileira de Estratégia e Relações Internacionais v.7, n.14, Jul./Dez. 2018 
caráter logístico como projetos, gestão de dados, software e logística operacional.

A opção do Brasil pelo MC Catalog (Materiel Codification Catalog), um dos três da categoria COTS de base comercial, é a opção mais adotada (I9 dentre os 47 membros do catálogo), e trata de um sistema comercial desenvolvido pela empresa tcheca AURA, com interface amigável e baseado na web. ${ }^{6} \mathrm{~A}$ partir da implementação pelo Brasil do sistema, o país participa com acesso aos produtos e serviços oferecidos, mas também, como agente classificador de indústrias brasileiras para serviços e produtos incluídos no catálogo. Tal sistema obriga o Brasil a protocolizar padrões de produção, informação e oferta ao mercado em matéria de defesa e segurança, o que faz do país um partícipe "quase-completo", uma vez que não é membro do sistema OTAN.

Se essa inclusão no Catálogo é objeto de interesse pelo aspecto da diversificação econômica e internacionalização do Brasil e da sua base industrial, tal como previsto nos documentos de defesa, o escopo dessa representação pode ter efeitos em outras áreas importantes como a interoperabilidade entre Forças Armadas, integração regional e a relação com estados vizinhos, a relação bilateral e multilateral com atores da OTAN, entre outros aspectos ainda não estimados.

Nos Estados Unidos, um relatório endereçado em 2002 ao Subcommittee on Readiness and Management Support Committee on Armed Services do Senado, por parte do United States General Accounting Office, teve como foco os esforços para gerenciar a competição e o aumento de preços por parte da Agência de Logística de Defesa (DLA). Àquela altura, a preocupação fundamental era com a decadência do sistema OTAN e da possibilidade de que os esforços em inovação pudessem continuar nos mesmos passos do período da Guerra Fria, uma vez que, no período que se seguiu, os efeitos do desarmamento puderam ser sentidos pelos EUA em termos de desenvolvimento (Cooper 2002).

A preocupação visível por meio do relatório era a de que os preços pudessem alcançar uma faixa de razoabilidade entre o custo do desenvolvimento e o retorno (ROI - Return on Investment) (Cooper 2002), por meio da atualização da base logística de ligação entre produtores e compradores. As críticas aos sistemas anteriores eram direcionadas à baixa capacidade de atualização e, portanto, pouco reflexo nos padrões de preço praticados no mundo ordinário. Além disso, um sistema de informações que garantisse exposição e competitividade poderia ser altamente produtivo para o sistema de compras dos

6 Para ter acesso aos países e tipos de catálogo utilizados, acessar http://www.nato.int/structur/ AC/I35/main/links/tools_codification.htm 
A Mobilização da Base Industrial de Defesa na América do Sul por Meio da Inserção Brasileira no Sistema OTAN de Catalogação

Estados Unidos. Por tratar-se de um dos sistemas mais complexos do mundo envolvendo produtores e compradores, incluindo eixos de relação multilateral e bilateral, o sistema de catalogação adotado pela OTAN gera implicações para dentro e para fora da estrutura daquela organização.

O Brasil se insere no sistema por diferentes motivos. Com o fim da Guerra Fria, o papel dos atores no sistema internacional foi sendo revisto, inclusive, dos regimes em curso com efeito militar. O Tratado da Aliança do Atlântico Norte (OTAN), como um regime moldado pelo conflito Leste-Oeste, também foi recondicionado às demandas do fim do século XX, começando com a Guerra na Bósnia, em que o imperativo já era voltado às missões de paz (Gaddis I992).

O caso brasileiro é particular por várias razões, algumas delas expressas anteriormente. Como consequência da Política Nacional de Defesa (PND), da Estratégia Nacional de Defesa (END) e do Livro Branco de Defesa Nacional (LBDN), o marco regulatório da BID, em que se destaca a Lei I2.598/20I2, regulamentada pelo Decreto 7.970/2013, consolida o segundo eixo estruturante dentre os três estabelecidos na END. A tradução desse compromisso pode ser simplificada pela (I) promessa de tornar o sistema de defesa com maior autonomia, (2) aumentando a eficiência, reduzindo custos, e (3) garantindo maior interoperabilidade entre as forças armadas. Nesse sentido, a catalogação e o mapeamento deste sistema, com vistas à sua internacionalidade, pode acelerar este processo.

Todos esses condicionantes expressos nos três documentos de defesa (PND, END, LBDN), reforçados pelo marco regulatório da BID, manifestam o interesse de desenvolvimento de um modelo que combine os anseios de expansão e crescimento às características já presentes de pujança em matéria de recursos naturais, populacionais, território. Embora o projeto de participação nos fóruns internacionais com proporcional desenvoltura tenha sido afetado pelo avanço da crise econômica e política doméstica, a participação brasileira no sistema de catalogação da OTAN parece ter sido um investimento de baixo custo, proporcionado pelo ensejo de defesa do assento permanente no Conselho de Segurança, o que normalizaria o sistema brasileira diante da maior parte dos membros do conselho.

Note-se que o Sistema OTAN de Catalogação é formado por países membros e não-membros e essa configuração também se modifica ao tempo das relações mais ou menos estáveis entre parceiros no sistema e fora dele.

A crise da Crimeia (20I4) levou à cisão desse sistema recentemente entre Russos e a OTAN, quando a Criméia foi anexada à Rússia e deixou de ser uma unidade autônoma com possibilidades de estreitamento com a União Europeia (Pereira 20I0). Naquela frente, União Europeia e Estados Unidos 
apoiaram fortemente a Ucrânia no enfrentamento da decisão quanto à Criméia, o que pode ter contribuído para que os russos deixassem de integrar o sistema como fornecedores de um grande grupo de itens e serviços, agora recatalogados por outros membros do sistema. Mas é importante ressaltar que os países do antigo Pacto de Varsóvia e que hoje fazem parte da OTAN, Hungria, República Tcheca, Eslováquia, Polônia, Romênia, dentre outros, e que desenvolveram bases industriais de defesa com origens ou suporte em tecnologias russas, mantêm relacionamento com a indústria de defesa russa. Sem contar o grande número de países que pertencem ao SOC e que empregam material de procedência russa - o Brasil é um caso e, a Índia, talvez o mais relevante.

Embora o aumento das tensões das relações provoque um alto grau de incerteza quanto ao abastecimento e relações de confiança mútua geradas pelo sistema comum de fornecimento de material de defesa - uma outra consequência possível pelo grau de transparência do sistema -, a interdependência entre esses atores é dificilmente quebrada por um só sistema. O fato da saída de um ator importante não implica a desestruturação do sistema, uma vez que permanecem vínculos de outra natureza.

Esse caso nos permite considerar que as dinâmicas relacionadas à economia da defesa estão diretamente associadas ao grau de proximidade e confiança entre parceiros, o que provoca um entendimento sobre o sistema ainda mais particularizado (Sandler \& Hartley 200I; Sandler \& Hartley 2007; Mesa 20I2). Isso não quer dizer que, entre atores presentes no sistema, não haja tensões relevantes. A máxima popular que diz "se não é contra eles junte-se a eles" também encontra paralelo nos estudos de economia de defesa quanto aos arranjos cooperativos que se formam de maneira desproporcional entre atores, tanto em matéria de força, quanto em robustez econômica (Olson I966).

Diante da retirada de um importante fornecedor e com o processo de nova catalogação como responsabilidade de outros atores do sistema, novas dinâmicas são incorporadas, assim como os rearranjos produtivos também refletem sobre as relações no sistema internacional. É relevante, pois, destacar que, apesar dos documentos de defesa brasileiros entre a primeira e segunda décadas de 2000 revigorarem a plataforma autonomista e desenvolvimentista do Brasil (Dagnino 2008), em matéria de política externa as relações autonomistas tiveram um aporte político relevante as últimas décadas, tanto pelo projeto de autonomia pela integração, quanto pelo projeto de autonomia pela diversificação (Vigevani and Cepaluni 2007).

Da mesma forma que propostas Sul-Sul tiveram lugar nos diferentes projetos políticos do Brasil das últimas décadas, as relações Norte-Sul tam- 
A Mobilização da Base Industrial de Defesa na América do Sul por Meio da Inserção Brasileira no Sistema OTAN de Catalogação

bém ocorreram circunstanciadas pela continuidade, solidez ou ausência de alternativa, no mesmo período. Ao mesmo tempo é possível que se defenda a presença de um paradigma dominante de política externa, presente nos últimos governos - que representaram ondas de ação prioritária e modelos distintos de desenvolvimento, ora focados na abertura e em relações pragmáticas, ora focados em relações horizontalizadas (Vigevani \& Cintra 2003; Vigevani and Cepaluni 2007).

Nesse caso, as relações derivadas da inserção no SOC podem se enquadrar no escopo de relações Norte-Sul, cujos lastros de dependência provocam uma expectativa de desproporcionalidade e de limitada capacidade de mudança de status por atores menores. Por outro lado, a não inserção em sistemas universais como o da OTAN pode deixar esses mesmos atores fora da competição, com qualquer parcela desse sistema. E ainda, a respeito das tensões, elas continuam existentes e acontecem a despeito da participação desses e de outros sistemas de cooperação que, dependentes dos atores e interesses individuais, estão constantemente em revisão. Enquanto estão presentes os 29 países da OTAN, são I3 países na categoria Tier 2, e outros 2I na Tier I7, perfazendo um total de 34 países usuários fora do sistema OTAN.

\section{Desafios do Sistema de Catalogação para o Brasil}

Dentro dessa conjuntura, uma das iniciativas teve como objetivo buscar o conhecimento das cadeias produtivas de modo que se propusesse um projeto de gestão de conhecimento sobre a Base Industrial de Defesa (Conhecimento da Base Empresarial de Interesse da Defesa). Esse é o projeto que está atualmente em curso entre o Ministério da Defesa e empresas, cujo modelo de desenvolvimento aplicado buscava, dentre outros objetivos, a retomada da indústria de navios de superfície, propiciando a relação eficiente entre a Marinha do Brasil, Ministério da Defesa, de um lado, e fornecedores, do outro. A iniciativa não visou somente meios navais, ela foca todos os produtos classificados como estratégicos e de defesa (PED/PRODE) das empresas enquadradas pela Comissão Mista da Indústria de Defesa como empresa de defesa (ED) e empresa estratégica de defesa (EED). O Plano de Articulação e de Equipamento da Defesa (PAED) tem na catalogação um mecanismo para impulsionar a capacidade tecnológica e logística do Brasil, mobilizando o conhecimento sobre: exportações, importações, identificação, empresas, cadeia produtiva, relação com outras agências como a Receita Federal, dados sobre

7 Disponível em https://www.nato.int/structur/AC/r35/main/links/contacts.htm, accessed May IO, 2018.

198 Austral: Revista Brasileira de Estratégia e Relações Internacionais v.7, n.14, Jul./Dez. 2018 
aplicabilidade, dados técnicos padronizados, atividades econômicas relacionadas, entre outros. O marco regulatório da Base Industrial de Defesa (BID) prevê essa obrigação quanto à catalogação.

A conjuntura em que foram feitos os documentos de defesa apontava o crescimento do Brasil em cenário de ascensão de países emergentes, em um período favorecido quer pela ciclotimia econômica quer pela maior estabilidade política do que antes (Dagnino 2008). Daquela conjuntura emergia a necessidade de projetar novas oportunidades por meio de parcerias internacionais possíveis.

Em 2013, o Decreto $7970^{8}$ estabeleceu a criação da Comissão Mista da Indústria de Defesa - CMID, "tendo por finalidade assessorar o Ministro de Estado da Defesa em processos decisórios e em proposições de atos relacionados à indústria nacional de defesa". Com isso, referenciados os dispositivos da Lei I2.598, de 20I2, a Comissão Mista se caracterizou por tratar a matéria, pela primeira vez, com base na relação interministerial. Em coordenação com o SISMICAT (Sistema Militar de Catalogação das Forças Armadas), atual Sistema de Catalogação de Defesa - SISCADE, o catálogo da OTAN fortaleceu o cumprimento das métricas, já que a expansão para este mercado poderia suprir demandas antes voltadas ao monopsônio do governo nacional (Sandler \& Hartley 2007). Além do Catálogo, o cumprimento dos fundamentos normativos do Ciclo de Vida do Produto, gestado pela AC327 no âmbito da OTAN, asseguraria os padrões de internacionalização da BID requeridos pela OTAN.

Por meio do supracitado Decreto, foram estabelecidas algumas das normas onde as empresas cadastrantes de produtos de defesa e produtos estratégicos de defesa gozam do termo de licitação especial, como parte do fomento federal ao setor, para efeito do sistema de aquisições

O mapeamento e controle da BID, atrelado à oportunidade do catálogo, pode proporcionar um modelo integrado com repercussões sobre a otimização dos usos entre as Forças de mesmos objetos de maneira não antes vista. A partir dos marcos criados no Brasil surgem os conceitos de produto, base de defesa, sistema diferenciado de licitações para empresas estratégicas, por meio da criação de sistema fiscal próprio. O sistema de catalogação de indústrias de defesa (SISCADE - Sistema de Catalogação de Defesa) se refere a este desenvolvimento.

O sistema em questão também foi implementado com foco no alinhamento da cadeia de suprimentos com o sistema de indústria, de modo a viabilizar também a articulação de um plano logístico para o sistema de defe-

8 Disponível em http://www.planalto.gov.br/ccivil_03/_ato2oII-20I4/20I3/decreto/d7970. htm, accessed May Iо, 2018. 
A Mobilização da Base Industrial de Defesa na América do Sul por Meio da Inserção Brasileira no Sistema OTAN de Catalogação

sa. O principal problema derivado de um eventual desalinhamento é causado porque sistemas e subsistemas podem criar alta dependência quando não há uma catalogação, de modo que um meio pode ficar inoperante caso um produto não esteja à disposição do planejamento no momento exato da demanda. Assim, a catalogação pode preencher este papel dando visibilidade ao planejador (Taylor 1982; Ourts 2003). Isso inclui os processos ligados à gestão de ciclo de vida de produtos, em que o Brasil participa mais recentemente.

A visibilidade das bases industriais de defesa é a principal tarefa da base de dados do catálogo OTAN. Sessenta e três (63) países fazem parte do catálogo, dentre os que estão no sistema OTAN e fora dele . Dependendo do tipo de participação, países externos ao sistema podem ter acesso como registradores ou podem somente ser consultantes. Nesta base atualmente são cerca de 34 milhões de itens catalogados por meio do esquema descrito acima. Dentre os usuários, cerca de 28 milhões participam deste sistema.

Dentre os países registradores, o Brasil tem cerca de I,I milhão de itens catalogados. Atualmente, são 3000 empresas que existem no sistema, desde empresas de mobilização, logística, até produtos de defesa ${ }^{9}$. Um conjunto de acordos (como clausula de catalogação) beneficia o sistema, controlado pela NSPA, agência da OTAN localizada em Luxemburgo. As exigências para que um país possa participar deste sistema começam com a criação do seu próprio sistema, tal como o Brasil o fez por meio do SISCAD. Os sistemas de catalogação das Forças Armadas mantem-se sob o SISCAD, onde as empresas partícipes foram autorizadas por lei a participar do sistema, como é o caso da EMGEPRON e da AVIBRAS.

O Brasil faz parte do Fórum de Diretores Nacionais de Catalogação da OTAN que acontece duas vezes por ano, sendo o diretor brasileiro do catálogo o responsável pela comunicação com a OTAN. Além da participação no sistema OTAN de catalogação permitir acesso contínuo à base de fornecedores mais diversificada e segura em matéria de defesa, o Brasil tem permissão para fazer registro de produtos e serviços brasileiros e de países parceiros, o que aumenta significativamente o uso e as possibilidades para a BID nacional. Do ponto de vista institucional é a Chefia de Logística e Mobilização e a Secretaria de Produtos de Defesa que trabalham mais diretamente em benefício do catálogo. Existe uma estrutura de governança para o SOC: fórum dos diretores nacionais de catalogação (no caso do Brasil, o diretor do CASLODE que responde pelo NCB brasileiro - National Codification Bureau); Painnel A avaliação do sistema; TSG, Transformation Steering Group - transformações conceituais e tecnológicas no sistema; e Comitê de Estratégias e Negócios,

9 Disponível em https://www.egn.mar.mil.br/arquivos/cepe/seminario-3-20ı6/CPLP_ Workshop_260UT20ı6.pdf, accessed May io, 2018.

200 Austral: Revista Brasileira de Estratégia e Relações Internacionais v.7, n.14, Jul./Dez. 2018 
BSC. O Brasil participa de todos os fóruns.

A característica mais relevante do processo é, de certo, a capacidade do Brasil de fazer-se presente no Catálogo OTAN por meio de suas empresas e, em especial, como alavanca de empresas de países parceiros. Um exemplo recente foi o caso da Suécia, até recentemente país Tier I do Sistema OTAN que usava serviços da Noruega, país membro da OTAN, para inserir seus produtos no SOC. O processo de evolução da Suécia para país TIER 2 no SOC, considerando a vendo dos caças Gripen ao Brasil, também pode ser citado como um efeito em cadeia.

Por iniciativas regionais, o assunto catalogação passou a ser discutido localizadamente, envolvendo países presentes ou não no Sistema de Catalogação - como a regional Pacific Area Cataloguing Seminar (PACS), onde participam vários países da Bacia do Pacífico, e Austrália e Nova Zelândia têm maior iniciativa de coordenação; também podemos citar o Nordic Defence Cooperation (NORDEFCO), formado por países nórdicos. E, por isso, fora sugerido que países sul-americanos fossem reunidos pelo CATSUL (Fórum Permanente sobre Catalogação dos Países do CDS UNASUL), onde a responsabilidade em termos de catalogação seria do Brasil (como país Tier 2) e o Chile assumiria a primeira presidência. Desde a criação do grupo, o Seminário Sul-Americano (o primeiro em Buenos Aires, 20I4) teve o papel de fomentar o desenvolvimento da logística na criação de eixos comuns de discussão ${ }^{\text {Io }}$. A partir disso, foi montado um termo de referência que visa estabelecer as bases do trabalho em grupo. Dentre os objetivos centrais estão a ampliação da interoperabilidade logística, a integração das bases industriais, o estabelecimento de uma base única de catalogação para uma linguagem comum entre sul-americanos.

O impulso econômico esperado com este tipo de iniciativa é da possibilidade de criação de uma base comum de investimentos, que foi observada pelo estudo do modelo de produção de VANT (Veículo Aéreo Não-Tripulado) brasileiro e da construção de aeronaves pelo Brasil e pela Argentina. Uma possibilidade aventada por conta do desenvolvimento deste modelo integrado está relacionada à fabricação de Navios-Patrulha.

Atualmente, Peru, Chile, Colômbia e Argentina também fazem parte do grupo da UNASUL de padronização do catálogo, onde o Brasil é mobilizador e indutor da catalogação. O Brasil gerencia a sua base através da nuvem do Sistema de Catalogação que está localizada no Exército Brasileiro, onde a função de defesa cibernética se concentra. A acessibilidade do catálogo pela internet faz do catálogo consultável e administrável entre parceiros, embora

Io Ver Termo de Referência do Fórum Permanente dos Países do CDS UNASUL sobre Catalogação. 
A Mobilização da Base Industrial de Defesa na América do Sul por Meio da Inserção Brasileira no Sistema OTAN de Catalogação

os cuidados com este depósito sejam muitos.

Como ferramenta para o conhecimento da base industrial de defesa, o subsistema que integra o Catálogo da OTAN viabiliza a divulgação e o conhecimento dos produtos e serviços disponíveis, montando as bases de uma plataforma para a gestão do conhecimento da BID. Nesse caso, assim como na existência de sistemas de gestão particulares das Forças na década de 90 , a criação de subsistemas integrados especializa a oferta e qualifica a demanda em matéria de defesa. Exemplo disso é o esforço em criar um subsistema próprio entre a Embraer e a Força Aérea. O Guia de Produtos de Defesa e o Catálogo de Empresas de interesse estratégico em Defesa são subprodutos desse sistema de banco de dados, e isso contribui para o sistema de mobilização nacional - atrelado à mesma Secretaria do MD a qual se subordina o sistema de catalogação. Outra iniciativa que pode ser citada como correlata foi a criação de um grupo de trabalho para a entrada do Ministério da Defesa na CAMEX (Câmara de Comércio Exterior) que, por sua vez, faz parte novamente do Ministério da Indústria, Comércio Exterior e Serviços (MDIC), tendo passado um ano sob escopo do MRE (Itamaraty), entre 2016 e $2017^{\text {II }}$.

Um dos casos citados em reuniões promovidas no âmbito da Federação das Indústrias do estado do Rio de Janeiro (FIRJAN) é o da formação de clusters voltados à Economia do Mar, já que um dos desafios trazidos a partir da formação do Catálogo foi sua utilização para os projetos de construção de navios-patrulha. No caso dos clusters marítimos em um país de litoral de grande proporção e atividade econômica considerável, clusters que envolvam institutos de pesquisa, indústria da pesca, a bacia hidrográfica, o transporte hidroviário, a indústria náutica de esporte e lazer e a indústria de reparação podem justificar os incentivos a fazer estes investimentos.

A Economia do Mar é um dos setores em franca expansão e a sua organização tem derivado de estudos que apontam um redirecionamento para investimentos associados à capacidade marítima associada à naval (Stavroulakis \& Papadimitriou 20I6). Tais incentivos têm sido revelados por conta das readaptações na indústria de defesa, em que tanto os meios devem ser cada vez mais associados à atuação diversificada, como suas construções calcadas em efeitos e transbordamento para setores correlatos e indiretos, onde mais setores podem ser incluídos como participantes desta economia de base do Catálogo da OTAN.

Assim, a indústria naval bélica pode ser beneficiada pela Economia do Mar no Rio de Janeiro, por exemplo, onde essas ideias se concentraram, por

II Disponível em http://www.mdic.gov.br/noticias/243I-camara-de-comercio-exterior-voltapara-o-mdic, accessed May ıо, 2018.

202 Austral: Revista Brasileira de Estratégia e Relações Internacionais v.7, n.14, Jul./Dez. 2018 
meio da participação do Estado e do capital privado. O PAED incentiva essa interação, no que tange a retomada da indústria naval. O projeto das corvetas classe "Tamandaré" aponta nessa direção e estimula a participação do setor privado nessa indústria. Trata-se de uma nova classe de navios que aproveita a experiência das corvetas anteriormente produzidas no Brasil, em especial, da classe Barroso.

Um dos incentivos associados ao modelo de construção de um cluster marítimo em torno da construção de navios-patrulha ou da corveta Tamandaré pode ser explicado pelo modelo de Análise Insumo-Produto. Utilizou-se esse modelo para montar uma matriz de produtos, dividindo a economia em setores econômicos (cerca de iıo setores) e se calcula os fluxos entre setores com base na intensidade tecnológica e de produção. Como exemplo, a corveta classe "Tamandaré" utilizaria 34 setores econômicos, o que significa um alto impacto em outras atividades econômicas. Neste caso, são variáveis determinantes para que o projeto seja enquadrado com impacto socioeconômico: produto, valor do produto e nível de emprego. Neste caso, a corveta, cujo preço atual seria de cerca de I, 5 bilhão de reais, retornaria os investimento ${ }^{\mathrm{I} 2}$. O efeito multiplicador em salários, manutenção e instalações, também acontece por cada navio, gerando cerca de 7000 empregos.

Atualmente, merecem destaque dois clusters no Rio de Janeiro: o associado ao complexo de Itaguaí, voltado à construção de submarinos convencionais e com propulsão nuclear; e o do Arsenal de Marinha, mais antigo, que tem enfrentado desafios decorrentes das limitadas possibilidades de investimento.

Assim sendo, podem ser apontados como processos associados ao sistema de catalogação: a organização e a governança. Com isso, o efeito desejado maior do catálogo é a expansão do potencial de registro de produtos para o controle da cadeia de suprimentos e o gerenciamento do sistema de manutenção dos meios. Isso possibilitaria a criação de uma doutrina sobre a gestão do ciclo de vida, baseada no conhecimento integrado provido por estas iniciativas.

I2 Disponível em http://defesaeseguranca.com.br/marinha-vai-investir-us-ı8-bi-nas-novascorvetas-classe-tamandare/, accessed May Iо, 2018.

Sobre a matriz de insumo-produto e impactos na economia de cluster ver: http:// defesaeseguranca.com.br/marinha-vai-investir-us-ı8-bi-nas-novas-corvetas-classe-tamandare/ http://defesaeseguranca.com.br/wp-content/uploads/alte_edesio_apresentacao_grande_abc_ dez20I2.pdf, accessed May ıо, 20 I8. 


\section{Economia Política Internacional, Economia de Defesa e o mo- delo para análise das repercussões para o Brasil da inserção no NCS.}

O estudo aqui apresentado requer a detecção do modelo de catalogação desenvolvido pela OTAN, e dos processos que possibilitaram a inserção do Brasil no sistema. Para o principal o eixo da pesquisa, o método escolhido é o estudo de caso que, embora ofereça limitações como método para efeito de um sistema em curso, não seria apropriado fazer deste um estudo comparativo, uma vez que não há casos robustos em equiparação de variáveis. O enfrentamento principal deste problema se dá porque a proximidade entre a variável dependente - o catálogo como representante de um processo de amplificação e fortalecimento de atores parceiros - e a independente - o sistema e como ele acontece, são demasiadamente próximas.

“(...) Such biases can occur when the researcher selects cases that represent a truncated sample along the dependent variable of the relevant universe of cases (...). In statistical research, the standard presentation of selection bias suggests that a truncated sample typically understates the strength of the relationship between the independent and dependent variables (...)." (Bennett 2004, 48)

Embora tal proximidade seja apontada como um eventual "bias" sobre o objeto - o Catálogo da OTAN - não estão reduzidas as oportunidades de destacarmos institucionalidades, por meio de processos e rotinas que tenham impacto no sistema internacional e seus atores - dentro e fora do citado objeto. Por outro lado, se o estudo de caso pode nos oferecer o processo, o impacto econômico e político não pode ser observado somente à luz de seus condicionantes institucionais, em geral, demasiadamente burocráticos. O principal elemento a ser considerado aqui é a hipótese de que microprocessos criam rotinas e instituições que, de modo inverso, recondicionam relações políticas maiores. Este efeito sobre a política externa tem sido observado por meio da cooperação técnica, cooperação horizontal ou do institucionalismo incremental nas relações internacionais (Bevir 2008). De outro modo, também é importante considerar os condicionantes de um ator hegemônico como a OTAN.

Nessas condições, parece pertinente usar da Economia Política Internacional levando em conta argumentos de ordem institucionalista. Embora o modelo da Hegemonic Stability Theory (HST) possa oferecer elementos de partida que fortaleçam a particularidade do caso OTAN, convém reconhecer que há um papel limitador nas instituições criadas sob um modelo funciona-

204 Austral: Revista Brasileira de Estratégia e Relações Internacionais v.7, n.14, Jul./Dez. 2018 
lista. O ponto de contato entre esses métodos pode ser explicado: I) pelo fato de que o modelo do Catálogo da OTAN tem o signo de um projeto constituído na forma de uma aliança militar completa e cuja hegemonia se expressa pela robustez econômica daquela parceria e de seus membros 2) pela necessidade de aplicarmos consensos da teoria institucionalista e da cooperação, em que a arquitetura e os processos importam e a ambientação cooperativa gera lastros que aumentam o custo de saída do projeto (Gulati \& Singh I998; Moravcsik I999). Ou seja, se há elementos de hegemonia em ação com elementos cooperativos e institucionalistas, o ambiente define-se híbrido e, portanto, passível de observação por meio de espectros metodológicos também híbridos ou combinados. É possível encontrar essa proposta em Moravicsik:

\begin{abstract}
Ainda assim, se as restrições vinculativas mais importantes na cooperação internacional eficiente são de fato nacionais e transnacionais, não intraestatais, parece plausível conjecturar que uma importante fonte de cooperação internacional autossustentável, mesmo em face de compromissos "inconvenientes", não é apenas a concentração de poder, como propõe a teoria da estabilidade hegemônica, nem a construção de fortes instituições internacionais per se, uma vez que a teoria do regime funcional tende a enfatizar, mas as mudanças sociais e políticas nacionais e transnacionais que "bloqueiam" a cooperação, encorajando a adaptação social que é difícil de reverter - um argumento consistente com a teoria das relações internacionais liberais (Moravicsik I999, 302 - tradução nossa).
\end{abstract}

Portanto, seguindo essa escolha, a opção teórica é determinada pela presença de um ambiente cooperativo, observado sob a liderança de alguns - com predominância de um deles, os EUA - e demais estados considerados caronas (Olson I966). É importante observar esse sistema como parte da escolha, uma vez que a apreensão do caso parece estar robustecida por uma análise empírica que comporta essa premissa. E por ela, que seja possível compreender dinâmicas e ressonâncias do processo, inclusive, para o Brasil, por meio dessa inserção como quase-ator do sistema de catalogação (não sendo membro ou sócio da OTAN).

A ponderação principal da teoria HST a respeito da estabilidade do sistema como baseada em um poder hegemônico pode ser também considerada, mas, como método, importa a condução do processo como parte do sistema onde esta força motriz pondera e onde os demais estados têm menores chances e opções. Dito isso, sabida a pouca mobilidade em relação às alternativas, o Brasil, constituindo um ator possível e externo, é uma experiência inédita que deve ser melhor observada se consideradas tais condições anteriormente explicadas. 
A Mobilização da Base Industrial de Defesa na América do Sul por Meio da Inserção Brasileira no Sistema OTAN de Catalogação

A Economia Política Internacional, neste caso, permite-nos observar o objeto sem a definição precisa de variável dependente e variáveis independentes, de modo que importam as relações entre os mercados e as condições políticas do caso (Milner ı998; Milner 2004, p.285; Gilpin 2016). Contudo, outro aspecto relevante que pode nos subsidiar é a economia de cluster e o que a política de redes nos ensina a respeito da criação de relações exponencialmente importantes a partir de primeiras ligações (Porter 2003).

Em que pese a conjuntura econômico-política ser marcada por uma dinâmica variável e instável, é possível partir de conjunturas possíveis que interpelem tanto o cenário brasileiro quanto o cenário internacional em que a OTAN está inserida, uma vez dotados das premissas anteriores calcadas na incerteza. Nesse caso, a nossa proposta é aliar os dois cenários, na formulação combinada entre eles que nos permita conduzir as forças motrizes (driving forces) em relação aos cenários que destacamos como mais relevantes para este estudo. Assim, como resultado dessa combinação destacaremos quatro cenários possíveis que apresentaremos aos respondentes deste estudo, face às forças motrizes resultantes da nossa observação sobre o Sistema OTAN de Catalogação (SOC) e a incidência do e para o Brasil desse movimento.

Exatamente porque, na altura de 2017 , o cenário brasileiro para os próximos anos é de baixa expectativa de crescimento e, ademais, vigoram dúvidas a respeito da saúde do modelo OTAN como equilíbrio de contribuição entre atores, a inserção do Brasil nesse sistema em condições de pouca competitividade e baixo nível de investimento pode ser distinta do que o planejado. Certamente o alinhamento entre o planejamento e as conjunturas futuras é ainda mais determinante no caso dos sistemas de defesa, porque o imperativo do longo-prazo é mais afeto à economia de defesa do que a outras economias de alta variabilidade e de curto-prazo (Mesa 20I2; Sandler \& Hartley 200I; Sandler and Hartley 2007).

Em sendo a nossa tarefa destacar um caso de relevância e tratar de propor cenários possíveis que tenham implicação à política de defesa do Brasil, nossa proposta parte do cruzamento entre:

Na OTAN: (IA) uma revitalização do sistema com aumento da confiança e redistribuição de custos mais proporcional à participação e tamanho dos atores; (2A) a decadência do modelo de aliança militar, com aumento da insatisfação com a OTAN e da crise de regimes cooperativos, com aumento dos custos vertiginosamente.

No Brasil: (B) um cenário de recuperação franca associado aos índices de crescimento de países em desenvolvimento a partir dos próximos anos; (2B) um cenário de crise continuada pelos próximos anos com crescimento reduzido. 
Em se considerando a literatura pertinente à OTAN (Olson I966; Sandler and Hartley 200I) e à crise político-econômica do Brasil recente, respectivamente, a manifestação desses temas por meio destes cenários pode auxiliar, associadamente às forças motrizes destacadas por esta pesquisa e apresentadas em seguida, na construção de cenários possíveis, associados às consequências deles derivadas.

\section{Indicadores e resultados}

Para este trabalho foi feito um estudo dirigido à confecção e observação de cenários possíveis que envolvessem a participação do Brasil no Catálogo da OTAN para os próximos anos, conforme indicado a seguir:

\begin{tabular}{|l|}
\hline Cenários \\
\hline $\mathrm{IB}+\mathrm{IA}=$ Brasil estabiliza-se e cresce + OTAN se fortalece \\
\hline $2 \mathrm{~B}+2 \mathrm{~A}=$ Brasil cresce pouco ou não cresce + OTAN fragiliza-se \\
\hline $\mathrm{IB}+2 \mathrm{~A}=$ Brasil estabiliza-se e cresce + OTAN fragiliza-se \\
\hline 2B $+\mathrm{IA}=$ Brasil cresce pouco ou não cresce + OTAN se fortalece \\
\hline
\end{tabular}

\begin{tabular}{|l|l|}
\hline Forças motrizes (driving forces) & \\
\hline $\operatorname{Tr}$ & Transparência \\
\hline Ot & Otimização econômica em escala \\
\hline In & Internacionalização \\
\hline Op & Interoperabilidade \\
\hline
\end{tabular}

Além das entrevistas com profissionais diretamente ligados ao processo em questão, usamos o modelo de focus groups entre especialistas da área de administração e logística, relações internacionais e defesa e história militar. A metodologia de focus groups já está presente na literatura proveniente da psicologia e da sociologia há algumas décadas como um modo de recolher informações, impressões e opiniões de maneira sistemática e produtiva, porque baseada na premissa de que os agentes respondentes cooperam mais eficientemente em grupo do que por entrevistas individuais. (Kind 2008). O uso desta metodologia está amplamente relacionado à administração pública (Schröeder and Klerin 2009) e privada, em especial, quando é necessário detectar processos e aprimorá-los no curto e médio prazo, utilizando grupos 
A Mobilização da Base Industrial de Defesa na América do Sul por Meio da Inserção Brasileira no Sistema OTAN de Catalogação

de até I2 experts ou SME's (Subject Matter Experts). Alternativamente, é possível que se considere experts um grupo específico de: consumidores, fornecedores, empregados, dependendo da pesquisa em questão. Sua aplicação em estudos que convocam prospecção pode ser observada em McClure e Bertot (200I), pelos quais cenários possíveis e dados foram por meio deste método coletados.

Em conjunto com os nossos entrevistados - grupos de até seis pessoas com expertise ou conhecimento e experiência em defesa considerados alto ou muito alto na matéria - avaliamos a incidência nestes cenários, de elementos associados às quatro (4) forças-motrizes destacadas como principais para o Brasil na inserção deste sistema. Em cenários político-econômicos de crescimento e estabilidade e/ou crise e desestabilização para ambos atores, o Brasil e a OTAN, as forças-motrizes indicam elementos que traduzem os resultados esperados, ora com maior probabilidade de ocorrerem, ora com menor probabilidade. Com isso, importa destacar que estas forças-motrizes se comportam como ganhos possíveis, porque são considerados fatores motivacionais da proposta de inserção brasileira no sistema.

Contudo, ainda assim, há uma série de efeitos colaterais que também cumprem expectativas desta inserção e que podem ser também listados, em disposição com os resultados esperados e aqui propostos. Tais resultados são listados com especial enfoque nos resultados esperados, como os clusters locais e regionais, e na incidência para a atuação regional do Brasil. Este foco se dá porque o modelo proposto está inserido em uma proposta de política externa cuja preponderância brasileira no cenário regional aumentaria a estabilidade regional. Além disso, a participação brasileira em protocolos e sistema de alta internacionalização ampliaria a qualificação emergente entre atores principais do sistema internacional (Vigevani, Oliveira and Cintra 2003; Vigevani and Cepaluni 2007).

O primeiro cenário é qualificado pela boa desenvoltura econômica do Brasil e pela revisão do sistema OTAN com reposicionamento positivo diante das demandas contemporâneas.

O segundo cenário é marcado pela desestabilização continuada tanto da economia brasileira e da capacidade de desenvolvimento do país, quanto da OTAN de refazer-se diante das demandas e críticas ao seu sistema, face às novas políticas nacionais de seus principais atores ou à conjuntura internacional.

O terceiro cenário é marcado pela recuperação do crescimento brasileiro em índices razoáveis para países em desenvolvimento (de 2\% a $4 \%$ apontam institutos internacionais como a Oxford Economics até 2020). Nesse mesmo cenário combina-se à crise da OTAN diante dos dilemas contemporâ- 
neos de manutenção custosa de uma aliança e da existência de outros mecanismos mais eficientes para efeito dos problemas de segurança internacional, mais afetos aos países-membros.

O último dos cenários é, talvez, o mais crítico. Nele o Brasil sofre ainda da extensa crise econômica, com pequena capacidade de cumprir investimentos de longo prazo antes planejados e de robustecer o seu setor de defesa com base em compras governamentais e incentivos públicos. De outro modo, a OTAN ainda resiste, contudo, face às transições políticas derivadas da ascensão de novos governos menos voltados às estratégicas colaborativas, o arranjo financeiro de sua sustentação se fragiliza, assim como o caráter das suas missões é progressivamente contestado.

O documento Brasil 2035, elaborado pelo Instituto de Pesquisas Econômicas Aplicadas (IPEA) em conjunto com a Associação Nacional dos Servidores da Carreira de Planejamento e Orçamento (ASSECOR), foi lançado em junho de 2017 e contou com um trabalho desenvolvido ao longo dos últimos dois anos, liderado pela pesquisadora Elaine Marcial, que há anos trabalha em cenarização. O esforço, que reuniu uma série de instituições e pesquisadores de diversas áreas, inclusive a da defesa, tem alguns resultados que podem também importar à analise aqui proposta. O capítulo dedicado à Dimensão Político-Institucional, tem no subtema Inserção Internacional conclusões que apontam para a integração da América do Sul e atuação dos países emergentes como chaves da transição do sistema internacional pela qual passa o Brasil. A continuidade do diálogo em cooperação é mostrada com base em quatro exemplos históricos de cooperação entre parceiros da América do Sul, bilateral ou multilateralmente, como na criação do Conselho de Defesa Sul-Americano (CDS), ou antes, quando da parceria Argentina-Brasil no setor nuclear.

A consideração de que o Brasil continua um "líder receoso", conforme o documento Brasil 2035, sugere como fator mais relevante a timidez de investimento pela integração. Em resumo, o apontamento de que o sistema internacional está em transição provocaria a "incerteza-chave se o Brasil se beneficiará de um sistema internacional de poder” (Brasil 2035, I67).

Outra conclusão relevante é a que, apesar da continuidade do limitado engajamento eleitoral dos assuntos de relações exteriores e de defesa, outra incerteza-chave e "se o Brasil terá uma base industrial de defesa indutora de desenvolvimento" em 2035, o que é explicado pela volatilidade dos investimentos nessa matéria e do alcance desses investimentos no setor privado, considerado frágil. Outro ponto de incerteza é se a BID terá o alinhamento necessário em relação às necessidades das Forças Armadas. Isso porque os gastos em defesa, embora volumosos (entre os primeiros iI do mundo) não representam um montante relevante flexível para investimentos. Nesse 
A Mobilização da Base Industrial de Defesa na América do Sul por Meio da Inserção Brasileira no Sistema OTAN de Catalogação

caso, recursos extra-orçamentários são normalmente empenhados, além dos incentivos fiscais que acabam por representar outros ganhos nessa matéria também.

Os resultados gerados pelo focus group apontam para a importância da inserção brasileira, primeiramente, quanto à padronização do sistema de defesa e de produção, o que melhora as métricas de produção no médio prazo e aumenta o desejo de inserção com economias complementares às já disponíveis na plataforma OTAN. A abertura a novos mercados foi um fator citado de como de alta relevância tanto para efeito de cenário de crescimento do Brasil ou de crise, já que a quebra do monopsônio (um único comprador) parece ser a saída para a sustentabilidade do setor. Neste caso, pesaria o retorno doméstico positivo, que poderia ser atingido pela padronização e exportações em larga escala. Um fator citado como relevante pelo grupo é o dado de que as empresas constituintes da base industrial são, em maioria, pequenas e médias empresas, com capital limitado para sustentarem períodos de crise ou investimentos de longo-prazo sem sustentabilidade. Este elemento parece ser ainda mais relevante se presente em cenário de crise econômica no Brasil, em que expertises correlatas estão identificadas no mercado nacional e poderiam estar disponíveis ao mercado externo de maneira sistemática.

De outro modo, a combinação entre os cenários de crescimento do Brasil e de crise na OTAN poderiam configurar as perspectivas mais comprometedoras. Tendo como princípio a diversificação de seu modelo de política externa, uma questão que aparece é se as normativas da OTAN atendem aos outros compradores fora deste sistema. Enquanto o cenário de fortalecimento e reposicionamento da OTAN fortalece as expectativas dos cenários de crescimento e crise do Brasil, o cenário de crise da OTAN fomenta dúvidas a respeito das métricas e de seus variados usos em eventual saída do sistema. Embora seja bastante reduzida a chance de o Brasil desejar desalinhar-se neste escopo, há sempre custos associados à saída, tal como o reposicionamento de parceiros e a identificação de novos mercados.

De qualquer modo, ainda que sob escopo do catálogo como método e base de dados, as iniciativas do Ministério da Defesa apontam para essa diversificação típica, onde não cessaram, por razão do catálogo, negociações com agentes fora do sistema OTAN do catálogo, como a China, Rússia e Irã. A complexidade quanto aos produtos de defesa demonstra, justamente, a necessidade de padronização, associada à complexidade e expansão de mercados.

A intenção de participação no Conselho de Segurança por meio da obtenção de um assento permanente apareceu no focus group como um fator determinante para a opção pela inserção do Brasil no catálogo. Esse parece ser um elemento que, mesmo diante de um cenário de crise da OTAN pode- 
ria continuar a ser um elemento-força para o Brasil, uma vez que o catálogo aponta para a sistematização e padronização internacional em qualidade, inclusive.

Os cenários de crise do Brasil e crise do sistema OTAN combinados indicariam uma perda significativa e parcial, embora o processo de padronização ainda seja apontado como necessário pelo grupo, a despeito das crises em questão. Observe-se que o custo de inserção no sistema por parte de empresas é pequeno diante do investimento do Brasil em matéria de incentivos fiscais e internacionalização.

Sendo assim, as forças motrizes caracterizadas como transparência, otimização, internacionalização, interoperabilidade parecem estar em consonância neste processo e, segundo os respondentes, estabelecidas como expectativas reais desta inserção. Nesse sentido, a internacionalização aparece como pressuposto inicial, a transparência conquistada pela padronização, a interoperabilidade estimulada a luz dos meios cadastrados. A otimização parece ser consequência dos processos anteriores, assim como o resultado. Importa, pois, que a otimização seja tanto causa como consequência dessa inserção brasileira no catálogo, segundo os respondentes.

\section{Conclusões}

A adesão ao sistema de catalogação da OTAN representa uma inserção que carrega um registro de parceria, com implicações para as relações internacionais, em função da tendência progressiva da combinação entre elementos calcados na defesa coletiva e outros na voltados à cooperação pela segurança internacional (Viana 20I2). Muito embora a dinâmica de uma aliança militar esteja distante do modelo pregado pelas relações exteriores brasileiras, os subsistemas criados pela OTAN podem servir à organização do sistema de defesa brasileiro, notadamente no que tange à catalogação e gestão de ciclo de vida de produtos.

Tendo como base premissas presentes no documento Brasil 2035 (20I7) e observando os cenários escolhidos para efeito deste estudo, é possível concluir que a díade investimentos e eficiência parece ser central para um projeto mais estável de desenvolvimento atrelado à internacionalização da Base Industrial de Defesa. As recentes iniciativas em torno da negociação de entrada do Brasil na OCDE apontam não somente para uma tendência de política externa, mas de internacionalização de padrões e métricas mais atreladas aos índices de desenvolvimento do que antes.

A presença de outros atores nesses processos de internacionalização e 
A Mobilização da Base Industrial de Defesa na América do Sul por Meio da Inserção Brasileira no Sistema OTAN de Catalogação

padronização de protocolos, que estão fora do ambiente da aliança militar da OTAN propriamente dita, amplia os usos do regime em matéria de otimização do sistema de defesa e possibilita a inserção de países não antes presentes. Convém ressaltar que estão presentes 29 países da OTAN, I3 países registradores não-membros Tier 2 e 2I países Tier I, perfazendo um total de 34 países usuários do sistema de catalogação que não pertencem à OTAN.

Dentre os novos atores, como compradores e produtores no sistema, estão a África do Sul e Índia (configurando o regime do IBAS com o Brasil); o Chile, Peru, Argentina e Colômbia; a Suécia (com quem o Brasil estabeleceu um dos seus maiores contratos recentes - Gripen); Israel, Austrália, Indonésia e Japão, como países de robustez econômica em matéria de PIB. Um dado relevante para apontamentos futuros e possibilidade de prospecção é o fato que os países africanos com os quais o Brasil recentemente fortaleceu parceria poderiam compor um importante grupo de usuários por meio da plataforma brasileira, observados os benefícios esperados para o setor de defesa. Este pode ser mais um dos objetos deste investimento no eixo Atlântico.

\section{REFERÊNCIAS}

Axelrod, R. I984. The Evolution of Cooperation. New York: Basic Books.

Ay, A. 20I4. Tip: an economic NATO in formation. Turkish Policy Quarterly. I3 (2): III-II8, June.

Barbarello, J. J. et al. 2000. Commercial Off-the-Shelf Products in Defence Applications. Papers presented at the Information Systems Technology Panel (IST) Symposium held in Brussels, Belgium, 3-5 April.

Bennett, Andrew. 2004. Case study methods: Design, use, and comparative advantages. In Cases, Numbers, Models: International Relations Research Methods, edited by . Detlef F. Sprinz and Yael Wolinsky, I9-55. University of Michigan Press.

Brasil. Decreto nffl 8.978, de $\mathrm{I}^{\circ}$ de fevereiro de 20I7. Aprova a Estrutura Regimental e o Quadro Demonstrativo dos Cargos em Comissão e das Funções de Confiança do Ministério da Defesa. Diário Oficial [da] República Federativa do Brasil, Brasília, DF, 02 fev. 20I7. Disponível em: <http://www.planalto.gov. br/ccivil_03/Leis/LCP/Lcpi36.htm>. Acesso em: 20 jun. 2017.

. Lei Complementar nffl I36, de 25 de agosto de 20Io. Altera a Lei Complementar nffl 97, de 9 de junho de I999. Diário Oficial [da] República Federativa do Brasil, Brasília, DF, 26 ago. 2010. Disponível em:

212 Austral: Revista Brasileira de Estratégia e Relações Internacionais v.7, n.14, Jul./Dez. 2018 
$<$ http://www.planalto.gov.br/ccivil_03/Leis/LCP/Lcpi36. htm>. Acesso em: 28 jun. 2017.

. Lei nffl I2.598, de 22 de março de 20I2. Estabelece normas especiais para as compras, as contratações e o desenvolvimento de produtos e de sistemas de defesa; dispõe sobre regras de incentivo à área estratégica de defesa e dá outras providências. Diário Oficial [da] República Federativa do Brasil, Poder Executivo, Brasília, DF, 22 mar. 2017.

Manual do Sistema Militar de Catalogação (SISMICAT). 20I7. Ministério da Defesa. v. I, 2 ed. MD42-M-oI, 2003. Disponível em: <http:// www.defesa.gov.br/arquivos/File/legislacao/ emcfa/publicacoes/ md42_m_oI_manual_sismicat_vol_I.pdf>. Acesso em: I7 jun. 2017.

Cooper, D. 2002. "Defense Acquisitions: Status of Defense Logistics Agency's Efforts to Address Spare Part Price Increases". GAO-02-505. GAO Reports. I, Apr. 8.

Dagnino, Renato. 2008. "Em que a Economia de Defesa pode ajudar nas decisões sobre a revitalização da Indústria de Defesa brasileira?” Oikos (Rio de Janeiro) 7 (I).

Gaddis, John Lewis. I992. "International Relations Theory and the End of the Cold War." International Security I7 (3): 5-58. JSTOR, www.jstor.org/ stable/2539i29.

Gilpin, Robert. 20I6. The political economy of international relations. Princeton: Princeton University Press.

Gulati, Ranjay; Singh, Harbir. I998. "The architecture of cooperation: Managing coordination costs and appropriation concerns in strategic alliances." Administrative science quarterly 43 (4): 78I-8I4.

Hunter, Eric J. 2009. Classification made simple: an introduction to knowledge organisation and information retrieval. Ashgate Publishing, Ltd.

Industrial Focus. 2013. "Intimus Degaussers Listed in NATO Catalogue for Information Security Products (NIAPC)." Military Technology. 37, 7, 5, July.

Instituto de Pesquisa Econômica Aplicada (IPEA). 20I7. Brasil 2035. Cenários para o Desenvolvimento. Associação Nacional dos Servidores da Carreira de Planejamento e Orçamento. Brasília: IPEA, ASSECOR.

Keohane, Robert O. I998. "International institutions: two approaches." International studies quarterly 32 (4):379-396.

Kind, Luciana. 2008. "Notas para o trabalho com a técnica de grupos focais/ Notes for the work with focus group technique." Psicologia em revista, IO.I5: I24-I38. 
A Mobilização da Base Industrial de Defesa na América do Sul por Meio da Inserção

Brasileira no Sistema OTAN de Catalogação

Koch, Robert and Gabi Dreo Rodosek. 20I2. "The role of COTS products for high security systems." In 2012 4th International Conference on Cyber Conflict (CYCON 20I2). Proceedings, edited by C. Czosseck, R. Ottis and K. Ziolkowski, 413-428. NATO CCD COE Publications.

Krasner, Stephen D., ed. I983. International Regimes. Cornell University Press.

Kyriakopoulos, I. and D. L. Losman. 2005. "The Economics of Mobilization in the Information Age." JFQ: Joint Force Quarterly 37: 87-95.

Lima, Raphael Camargo. 20I5. "A articulação entre política externa e política de defesa no Brasil: uma Grande Estratégia inconclusa." 257 f. Dissertação (mestrado) - UNESP/UNICAMP/PUC-SP, Programa San Tiago Dantas, 20I5. Disponível em: <http://hdl.handle.net/II449/ı28080>.

Mcclure, Charles R. and John Carlo Bertot, ed. 200I. Evaluating networked information services: Techniques, policy, and issues. Information Today, Inc.

Mesa, Antonio. 2012. "Sobre La Naturaleza Y Alcance De La Economía De La Defensa." Documento de Opinión. Instituto Español de Estudios Estratégicos.

Milner, Helen. 2004. “The Analysis of International Relations: International Political Economy and Formal Models of Political Economy". In Cases, Numbers, Models: International Relations Research Methods, edited by . Detlef F. Sprinz and Yael Wolinsky, 284-310. University of Michigan Press.

I998. "International Political Economy: Beyond Hegemonic Stability”, Foreign Policy, No. IIo, Spring.

Moravcsik, Andrew. I999. "A new statecraft? Supranational entrepreneurs and international cooperation." International organization 53 (2): 267306.

Olson, Mancur and Richard Zeckhauser. 1966. "An economic theory of alliances." The review of economics and statistics 48, no. 3 (August): 266279.

Ourts, MJ. 2013. Defense Contracting: Actions Needed to Increase Competition. GAO Reports. I-36, Mar. 28.

Pereira, Carlos Santos. 20Io. "A NATO e a Rússia: uma parceria reservada." Nação e Defesa.

Porter, Michael. 2003. "The economic performance of regions." Regional studies 37, no. 6-7: 549-578.

Ramirez, Rafael, Malobi Mukherjee, Simona Vezzoli, and Arnoldo Matus Kramer. 20I5. "Scenarios as a scholarly methodology to produce "in- 
teresting research", Futures 71: 70-87.

Ram, Rat. I995. “Defense expenditure and economic growth.” In Handbook of defense economics, edited by Keith Hartley and Todd Sandler, 25I-274. Amsterdam: Elsevier Science B.V. Volume I.

Sandler, Todd and Keith Hartley. 200I. "Economics of alliances: The lessons for collective action." Journal of economic literature 39 (3): 869-896. , eds. 2007. Handbook of Defense Economics: Defense in a globalized world. Amsterdam: Elsevier Science B.V. Volume 2.

Schröeder, Christine da Silva and Luis Roque Klerin. 2009. "On-line focus group: uma possibilidade para a pesquisa qualitativa em administração." Cadernos EBAPE.BR 7 (2): 332-348.

Schultz, B and D. Dotson. 2015. "Getting the Best Value in a Source Selection?" Defense Acquisition Research Journal: A Publication of the Defense Acquisition University I5, no.3 (Nov): 2I-24.

Soares Silva, Isabel, Ana Luísa Veloso and José Bernardo Keating. 20I4. "Focus group: Considerações teóricas e metodológicas." Revista Lusófona de Educação, 26.

Stavroulakis, Peter J. and Stratos Papadimitriou. 20I6. "The strategic factors shaping competitiveness for maritime clusters." Research in Transportation Business \& Management I9: 34-4I.

Taylor, Phillip. I982. "Weapons standardization in NATO: collaborative security or economic competition?" International Organization 36 (I): 95-II2.

Viana, Rita Margarida Martins et al. 20I2. NATO: aliança ou organização de segurança?: análise de 1991 a 2010. Tese de Doutorado. ISCTE. Lisboa.

Vigevani, Tullo and Gabriel Cepaluni. 2007. A política externa de Lula da Silva: a estratégia da autonomia pela diversificação. Contexto internacional 29 (2): 273-335.

Vigevani, Tullo, Marcelo F. de Oliveira and Rodrigo Cintra. 2003. Política externa no período FHC: a busca de autonomia pela integração. Tempo social I5 (2): 3I-6I. 
A Mobilização da Base Industrial de Defesa na América do Sul por Meio da Inserção Brasileira no Sistema OTAN de Catalogação

\section{RESUMO}

Este artigo tem por objetivo descrever e analisar as condicionantes e repercussões da entrada do Brasil no Catálogo da OTAN (NATO Codification System - NCS) para a Base Industrial de Defesa nacional e desenvolvimento do país (cujo acordo é de abril de i997. A hipótese central é que, por meio deste processo, houve um progressivo condicionamento da indústria de defesa e correlatas em benefício de protocolização, o que ampliou a internacionalidade e alcance de agentes nacionais, como compradores e vendedores, dentro deste sistema e subsistemas. O artigo está dividido entre o exame do processo de inclusão do Brasil no NSC e das características e propósitos envolvidos e a análise das repercussões para o Brasil. Para isso, antes da análise das repercussões, há uma explicação do método utilizado, uma vez que os objetivos do artigo de consolidam por meio de uma visão prospectiva de médio prazo.

\section{PALAVRAS-CHAVE}

OTAN; Catálogo; Base Industrial de Defesa (BID). 